2 Sideris EG, Papageorgiou GC, Charalampous SG, Vitsa EM. Aspectrum response study on single strand DNA breaks, sister chromatid exchanges and lethality induced by phototherapy lights. Pediatr Res 1981;15:1019-23.

${ }^{3}$ Schwartz AL, Cole FS, Fiedorek F, et al. Effect of phototherapy on sister chromatid exchange in premature infants. Lancet 1978;ii:157-8.

${ }^{4}$ Vecchi C, Donzelli GP, Sbrana G, Pratesi R. Phototherapy for neonatal jaundice: clinical equivalence of fluorescent green and special blue lamps. J Pediatr 1986;108:452-6.

5 Ennever JF, Knox I, Speck WT. Differences in bilirubin isomer composition in infants treated with green and white light phototherapy. J Pediatr 1986;109:119-21.
6 Jacobsen J, Brodersen R. Albumin-bilirubin binding mechanism. Kinetic and spectroscopic studies of binding of bilirubin and xanthobilirubic acid to human serum albumin. $J$ Biol Chem 1983;258:6319-26.

${ }^{7}$ Ham WT, Muller HA, Puffolo T. Sensitivity of the retina to radiation damage as a function of wavelength. Photochem Photobiol 1979;29:735-43.

Correspondence to Dr Hani Ayyash, 2nd Department of Paediatrics, University of Athens, Aglaia Kyriakou, Children's Hospital TT, Athens, 115 27, Greece.

\title{
Indicators of malnutrition in leukaemic children
}

\author{
M S KIBIRIGE, P H MORRIS JONES, AND R F STEVENS \\ Department of Oncology, Royal Manchester Children's Hospital, Manchester
}

SUMMARY In 24 children with acute leukaemia a low serum albumin concentration ( $31 \mathrm{~g} / \mathrm{l}$ or less) and a median weight:height ratio of less than 0.95 on admission were indicators of severe weight loss.

Malnutrition is a problem in children with cancer. Severe weight loss and malnutrition as causes of morbidity and mortality were quantified by Cahill, who established that the loss of $30 \%$ of lean body weight was incompatible with life. ${ }^{1}$ There are many causes of cancer cachexia. Patients with leukaemia are often affected, and both acute weight loss at presentation and persistent malnutrition are commonplace. Acute weight loss may be due to anorexia, malabsorption, excessive energy loss, ineffective metabolic activity, chemotherapy, and psychosocial factors. Whatever the causes, children who are malnourished when treatment is started have a worse prognosis than their counterparts who are well nourished. ${ }^{2-4}$ This may be due to factors inherent in the disease, or may be the result of ineffective treatment being given while waiting for their nutritional state to improve. In this retrospective study we tried to find out the risk factors that would help predict which children would benefit from supplementary nutrition.

\section{Patients and methods}

Twenty four new patients with acute leukaemia aged between 1.2 and 14.8 years were studied. They were retrospectively divided into two groups of 12 children. Group I comprised four boys and eight girls who needed supplementary riutrition. In Group II were 10 boys and two girls who did not need supplementary nutrition. On admission all children had a standard physical examination including measurement of height and weight. All children were treated according to the protocol of the Medical Research Council Childhood Leukaemia Trial. During their stay in hospital they were weighed regularly. The parents were advised by the dietician on what to give their children to eat. The children were offered food from the hospital kitchen, but parents provided alternative foods if the children requested items that were not available. During the course of treatment, if a child lost more than $10 \%$ of the admission weight he or she was given either nasogastric Fortisan 2.09 MJ (500 kcal)/500 ml by nasogastric tube or total parenteral nutrition. Total parenteral nutrition was given to those who were too ill to tolerate nasogastric feeds or who were unlikely to benefit from enteral feeding because of diarrhoea and malabsorption.

On admission (in addition to the other recommended haematological and biochemical tests) serum albumin concentration was estimated, and this was monitored weekly thereafter. The data obtained were used to determine which group of children required supplementary nutrition during the course of their treatment and to find out if there were any features apparent on admission that would predict which children would need nutritional support. The median weight:height ratio was calculated as the ratio of weight over height divided by weight over height at the 50 th centile. ${ }^{5}$ The ratio may be expressed as a percentage. The paired $t$ test was used to analyse the results. 


\section{Results}

The mean value for median weight:height ratio for children in group I was significantly lower than that for children in group II. The mean (SD) values were $0.95(0.11)$ and $1.0(0 \cdot 1)$ or, expressed as a percentage, $95 \%(11 \%)$ and $100 \%(10 \%)$, respectively $(p<0.01)$ (Fig. 1). The mean value for median weight:height ratio was still significantly lower by the fourth week in hospital. The mean serum albumin concentration of children in group I was significantly lower than that of children in group II on admission, being $31.5(2.5) \mathrm{g} / \mathrm{l}$ in group I and 35.6

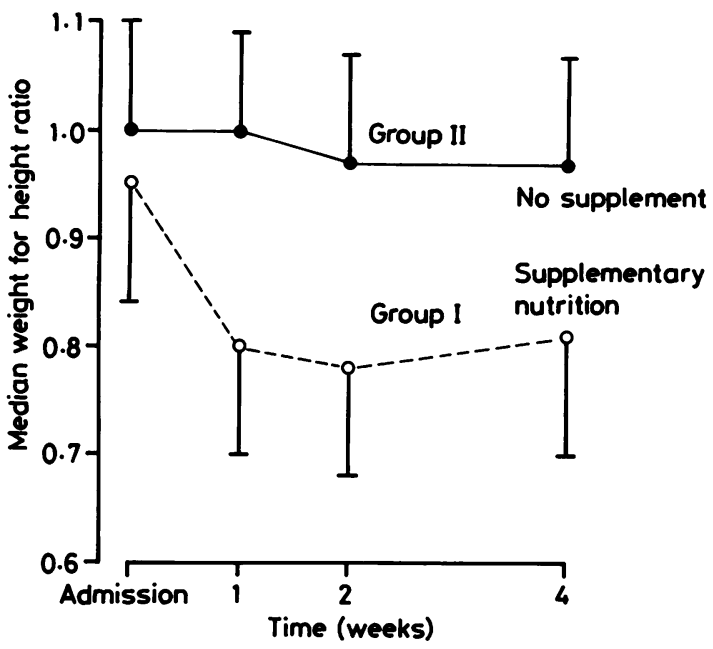

Fig. 1 Change in median weight:height ratio.

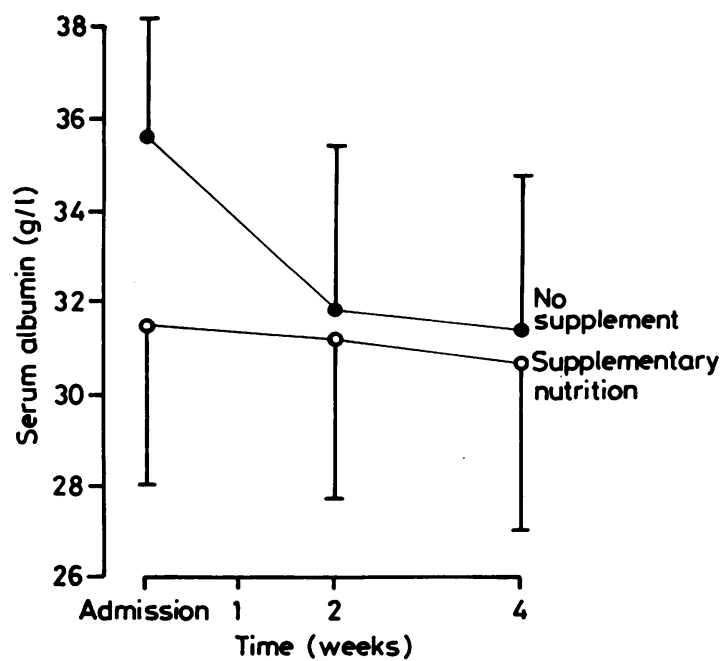

Fig. 2 Fall in serum albumin concentrations.
$(2.5) \mathrm{g} / \mathrm{l}$ in group II $(\mathrm{p}<0 \cdot 01)$, but not different at four weeks (Fig. 2).

\section{Discussion}

Although malnutrition is known in children with cancer, prospective assessment of nutritional state has not often been studied. For many children the start of chemotherapy tips the balance from adequate nourishment to malnourishment. Standard measurements of nutrition state need to be used regularly in these children, who at the time of admission may be on the borderline of adequate nutrition. We have found that the median weight: height ratio and the serum albumin concentration may be useful measurements in newly diagnosed children with leukaemia to indicate which children will require supplementary nutrition. Rickard et $a l^{6}$ published criteria for the nutritional staging of children with neoplastic disease. They suggested that a weight loss equal to or greater than $5 \%$ was bad. They also reported that if weight was below the fifth percentile when the height was greater than the fifth percentile, then the child was at risk of malnutrition. The third criteria was a serum albumin concentration of less than $32 \mathrm{~g} / \mathrm{l}$.

Actual weight at onset of symptoms is difficult to ascertain; we find the other two criteria more practical. In our study group those with a median weight:height ratio of less than 0.95 , and a serum albumin concentration of less than $31 \mathrm{~g} / \mathrm{l}$, were considered malnourished and needed supplementary nutrition. The median weight for height showed a dramatic fall and could be used for continuing assessment, but serum albumin concentration did not show the same reduction.

We thank Mrs $\mathrm{N}$ Woodward for help in preparation of the manuscript. MSK is supported by the Leukaemia Research Fund.

\section{References}

1 Cahill GF. Starvation in man. New Engl J Med 1970;282:668-75.

${ }^{2}$ Balducci L, Hardy C. Cancer and malnutrition - a critical interaction. Am J Hematol 1985:18:91-103.

3 Van Eys J. The pathophysiology of undernutrition in the child with cancer. Cancer 1986:58:1874-80.

${ }^{4}$ Donaldson SS, Wesley MN, De Wys WD, Suskind RM, Jaffe N. Van Eys J. A study of the nutrition status of pacdiatric cancer patients. Am J Dis Child 1981:135:1107-12.

5 Mclaren DS, Read WNC. Classification of nutritional status in carly childhood. Lancet 1972:ii:146-8.

${ }^{6}$ Rickard AK, Coates TD, Grosfeld JL, Weetman RM, Baehner RL. The value of nutritional support in children with cancer. Cancer 1986;58:1904-10.

Correspondence to Dr M S Kibinge, Department of Oncology, Royal Manchester Children's Hospital, Pendlebury, Manchester M27 1HA

Received 12 March 1987 